In order to exhibit the constancy of the lag in the occurrence of the gradient variations behind those of the sun-spots, as well as the remarkable similarity in form of the two oscillations, I have reproduced the above figures graphically in the accom. panying diagram, in which the baric gradient ahnormals are plotted out simultaneously with the invertel sun-spot abnormals :-

It will be observed that there is an almost uniform lag in the baric gradient curve behind the inverted sun-spot curve of a little more than a year, while a variation of 'or inches on the barometer scale corresponds very nearly throughout (allowance being made for the lag) to Io on the sun-spot scale.

As the strength of the prevailing west and scuth-west winds of these regions must necessarily depend on the amount of the baric gradient between places on the edge of the European continent like London, and those inland, and to the north as St. Petersburg, there is fair ground for concluding that the west and south-west winds must on the whole be stronger in years of minimum sun-spot than in those of maximum sun-spot.

Some direct evidence in favour of this notion has already been communicated to NATURE by Mr. S. A. Hill and Mr. Eilis of the Greenwich Observatory.

Moreover the amount of variation in the strength of the wind between London and St. Petersburg, following upon the change in the barometric gradient between the two during the cycle, should be enough to cause a sensible variation in the character of the weather; for according to Mr. Blanford the mean barometric gradient over the Bay of Bengal during the south-west monsoon is about $0^{\circ} 025$ inches in 100 miles.

Now as the distance from London to St. Petersburg is about 1300 miles; in order to maintain a current of air between them throughout the year equal to that of the summer monsoon in the Bay of Bengal, there would have to be a total annual barometric gradient of 0.0325 inches. As the range of the abnormal gradient in the rresent case amounts to 0.08 inches it should cause a variation in the wind equal to one-fourth that of the monsoon.

For the period 1822-71 the normal mean annual gradient from London to St. Petersburg is +0.098 inches. The variation of the abnormal is therefore nearly equal to the normal gradient.

Taking the results just obtained with those given by $\mathrm{Mr}$. $\mathrm{H}$. F. Blanford in his article in NATURE, vol. xxi. p. 477 , it may be concluded that there is a barometric "see-saw" between Russia and Western Siberia and the Atlantic coasts of Europe, similar to that between the former districts and Indo-Malaysia.

Just as in the latter case the relation will probably be found to be more marked in the winter months, and may also be found to explain some of the numerous facts already ascertained resarding variations in the rainfall, cloud, and temperature of Western Europe, at different epochs of the sun-spot cycle.

E. Douglas Archibald

\section{CONGRESS OF THE FRENCH LEARNED SOCIETIES}

THE session of the Congress of the French Learned Societies has llasted only three days, but has exhibited an unusual amount of interest. Many papers were read in the section of Science presided over by M. Milne-Edwards, the veteran member of the Institute.

M. Alluard summarised the results of rotation of the wind as registered by anemometers at an altitude where it is not to be feared that surface-friction should interfere. The number of rotations from north to south was iI 3 . Of these 83 were in the positive direction, or by east, and only 30 by west ; 49 of the 83 positive were continued to the west, and 34 stopped at the south or vicinity; consequently when a wind has come from north to south by east, the greater probability is that it will contimue rotating to the west. When it has rotated to the west the probability is even greater that it will continue to the north Again, of the 49 three-quarter rotations observed not less than 32 were completed, and only 17 stopped at the west and vicinity. The same thing cannot be said of the negative rotations : only 13 were from north to east, and of these only 6 were from north to north by west. These results are a confirmation of Dove's well known law.

General Nansouty, the director of the Pic-du-Midi Observatory, announced that the new buildings on the top of the mountain will soon be ready, and that next winter he will use them for taking readings. It is curious that the last winter has been one of unusual mildness in this exalted altitude.
M. Hébert read a long paper on the formation of cyclones, which he explains by the influence of mountain ranges on the great atmospheric currents loaded with humidity.

M. Vidal presented a photometer based on the action of light on a selenium element of the ordinary construction. M. Vinot, editor of $\mathrm{Le} \mathrm{Ciel,} \mathrm{presented} \mathrm{a} \mathrm{refractor} \mathrm{mounted} \mathrm{equatorially,}$ of which the price is less than $10 l$., with a magnifying power of 150 . M. Joubert gave details on the working of the Trocadéro Popular Observatory, which is now in constant operation, and where lectures on astronomical subjects are delivered regularly.

M. Guillemare read a paper on the use of soleine for lighting purposes. This product has been obtained by the distillation of a number of resinous matters, which have a point of ebullition from 150 to $I 60$ Centigrade and a mean density of 0.860 . When they have been freed from every other matter they can be used in a specially-prepared burner. This soleine can be prepared in immense quantities in all countries where pines are abundant.

A number of interesting communications were made on palæontology and zoology, generally advocating Darwinian views.

The final sitting was presided over, as usual, by the Minister of Public Instruction, and took place in the large hall of the Sorbonne. A number of crosses of honour and medals were distributed.

\section{UNIVERSITY AND EDUCATIONAL INTELLIGENCE}

OXFORD.-The lectures of the summer term commence this week. At the University Museum Prof. Clifton will conduct a class in practical physics and will lecture informally on the use of optical instruments. Mr. Stocker will give an experimental lecture in mechanics, and $\mathrm{Mr}$. V. Jones will lecture on mechanical problems, in continuation of their courses last term. Prof. Odling will continue his course of lectures on organic chemistry, and Mr. Fisher will finish his inorganic course.

At Christ Church Mr. Harcourt lectures on the metals, ant Mr. Baynes on the theory of gases. At Balliol Mr. Dixon gives an experimental lecture in elementary physics.

In a Congregation holden on Tuesday, April 27, it was resolved that candidates, not being members of the University, may present themselves at any of the ordinary examinations for Responsions. Last term a statute was passed insrituting an examination to take place in the Long Vacation. This examination, which can be passed by candidates before matriculation into the University, is to be passed in lieu of Responsions. The effect of the statute will be that all young men may pass $\mathrm{Re}$ sponsions before they matriculate, and less of their University time will be consumed in getting up school work.

The proposal to designate the unattached students as students of the University Hall was lost by a large majority, 90 voting against the proposal and only 9 for it.

\section{SOCIETIES AND ACADEMIES LONDON}

Chemical Society, April 2r.-Dr. Debus in the chair.-It was announced that a ballot for the election of Fellows would take place at the next meeting, May 5.-The following papers were read :-On the distillation of mixtures of carbon disulphide and carbon tetrachloride, by F. D. Brown. The objects of the research were to find the boiling-point of every possible mixture of the two liquids, and the composition of the vapour evolved by any mixture when boiling. Tables and curves giving these results accompany the paper. The author also finds that the composition of the vapour evolved is independent of the pressure under which ebullition takes place-On the estimation of hydric peroxide by means of potassic permanganate, by W. E. Adeney.-On the oxidation of sulphurous acid, by H. P. Dixon. The author finds that when sulphur dioxide, steam, and oxygen are exposed to a temperature of $100^{\circ} \mathrm{C}$. no diminution of volume takes place, and therefore no sulphhuric acid is formed. If the temperature be allowed to fall so that water condenses, a slight contraction in volume is observed.-On the reduction of cinnamic alcohol, by F. Hatton and W. R. Hodgkinson. When this substance is heated to $100^{\circ} \mathrm{C}$. for three or four days 